Supplement of

\title{
Delivery of halogenated very short-lived substances from the west Indian Ocean to the stratosphere during the Asian summer monsoon
}

\author{
Alina Fiehn et al. \\ Correspondence to: Kirstin Krüger (kkrueger@geo.uio.no)
}

The copyright of individual parts of the supplement might differ from the CC BY 3.0 License. 
The analysis of the radiosonde profiles of temperature, relative humidity, zonal wind, and the calculated gradient of the virtual potential temperature (Fig. S1) reveals a clear separation between subtropical and tropical circulation. The first part of the cruise shows high relative humidity in the Marine Atmospheric Boundary Layer (MABL), but very low in the rest of the troposphere (Fig. S1b), which revealed that there was low convective activity transporting water vapor upward in the subtropics. During the second, tropical part of the cruise, a temperature inversion layer, called trade inversion, exists at about $2.5 \mathrm{~km}$ height between July 24 and August 4, 2014, which we associate with the dry descending air masses of the lateral monsoon (Webster et al., 1998) and the Hadley Cell in the subtropics. The temperature inversion coincides with the upper boundary of a humid layer, indicating that it suppresses convection and exchange through this layer. The MABL upper boundary was below the inversion, and acted as a weaker transport barrier than the inversion, indicated by the lower values in the gradient of the virtual potential temperature, a measure for atmospheric stability, at $1 \mathrm{~km}$ height than at $3 \mathrm{~km}$ height (Fig. S1d).

Close to the equator, we find enhanced relative humidity in the middle and upper troposphere, which is a sign of enhanced convective activity. The winds north of the equator belong to the southwesterly monsoon winds, which transport West Indian Ocean air masses towards India. Close to the equator, a strong easterly jet, just below the tropopause, is visible. This relates to the upper part of the transverse monsoon circulation (Webster et al., 1998).

\section{References}

Webster, P.J., V. O. Magaña, T. N. Palmer, J. Shukla, R. A. Tomas, M. Yanai, T. Yasunari, Monsoons: Processes, predictability, and the prospects for prediction, J. Geophys. Res., 103, 14451-14510, https://doi.org/10.1029/97JC02719, 1998. 

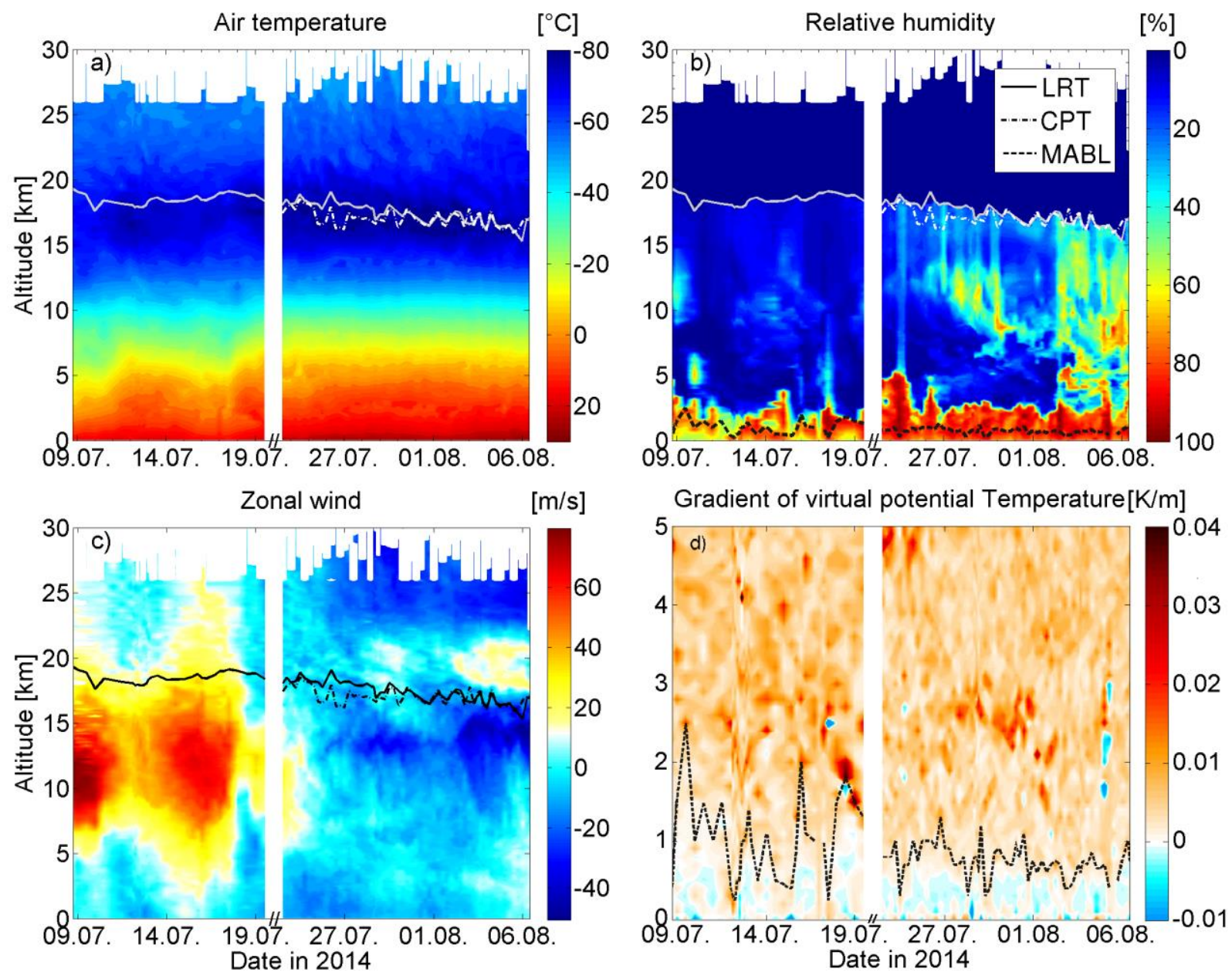

Figure S1: Radiosonde profiles of temperature, relative humidity, zonal winds and gradient of virtual potential temperature as time series for the OASIS cruise. The white gap denotes the harbor stop at Port Louis, Mauritius. LRT: lapse rate tropopause, CPT: cold point tropopause, MABL: marine atmospheric boundary layer. 

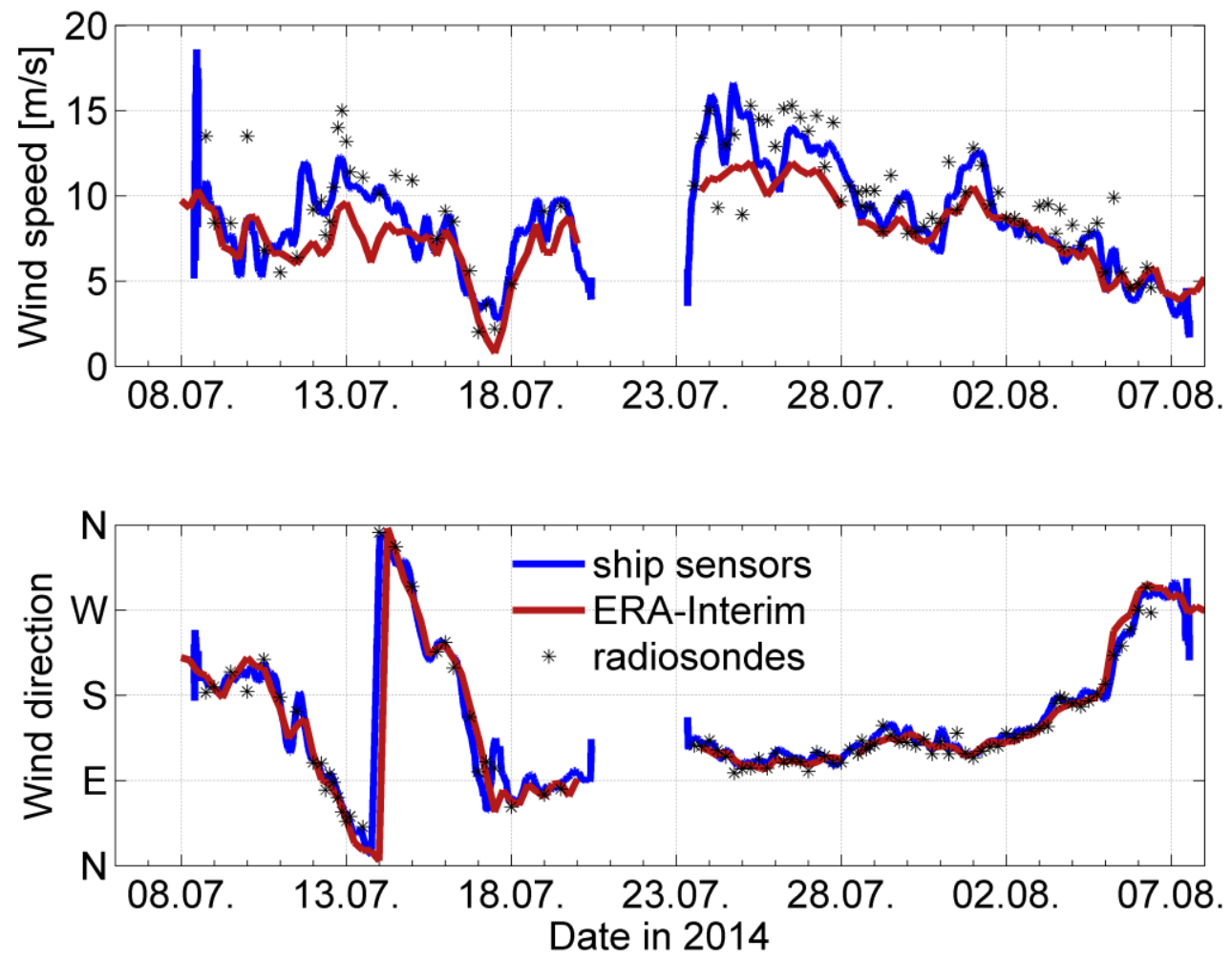

Figure S2: Wind speed and wind direction during the OASIS cruise from ship sensors and ERA-Interim reanalysis data (both as 6 hour mean) and radiosondes launched from the ship (as instantaneous measurement). 


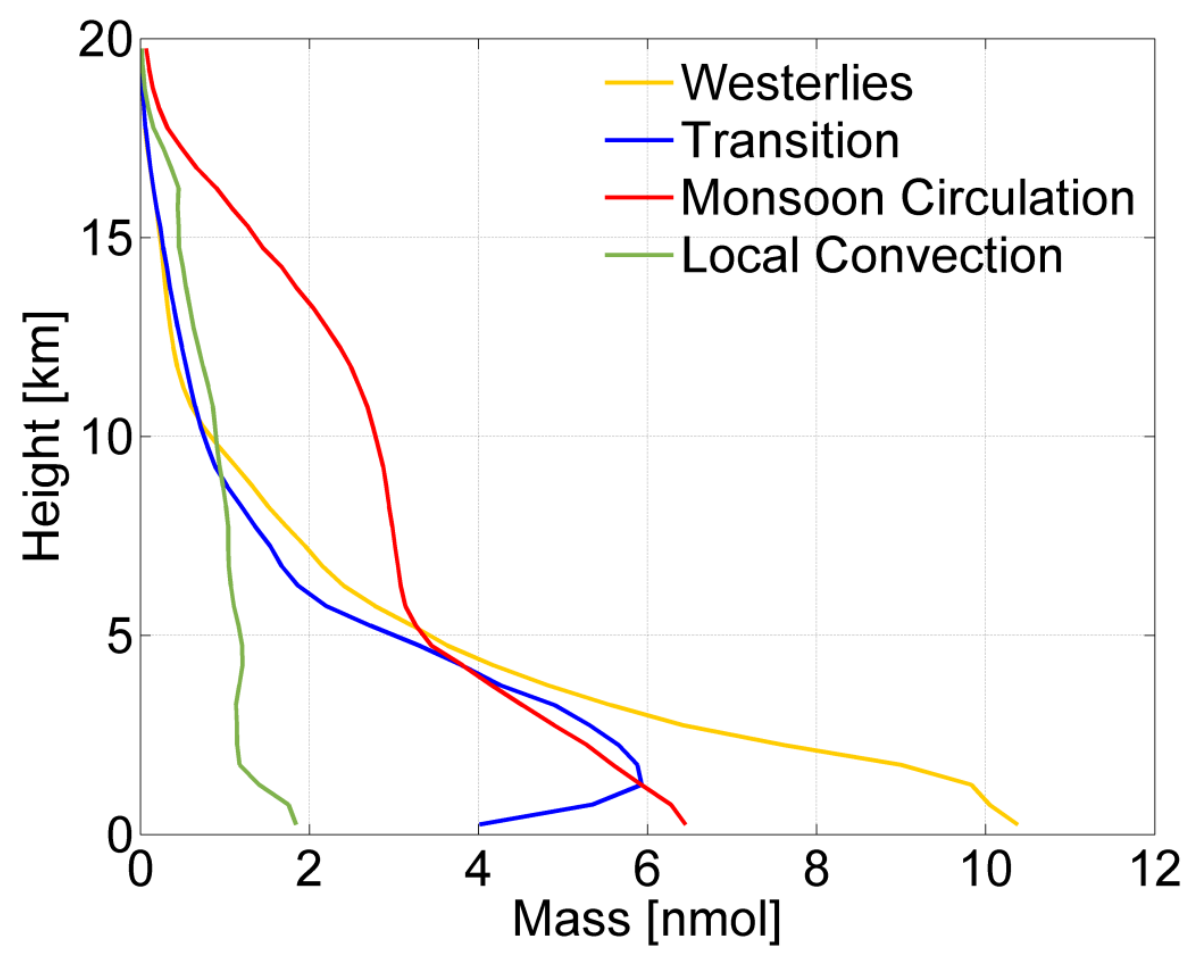

Figure S3: Time-averaged vertical distribution of bromoform in the four transport regimes (Figure 3b). 

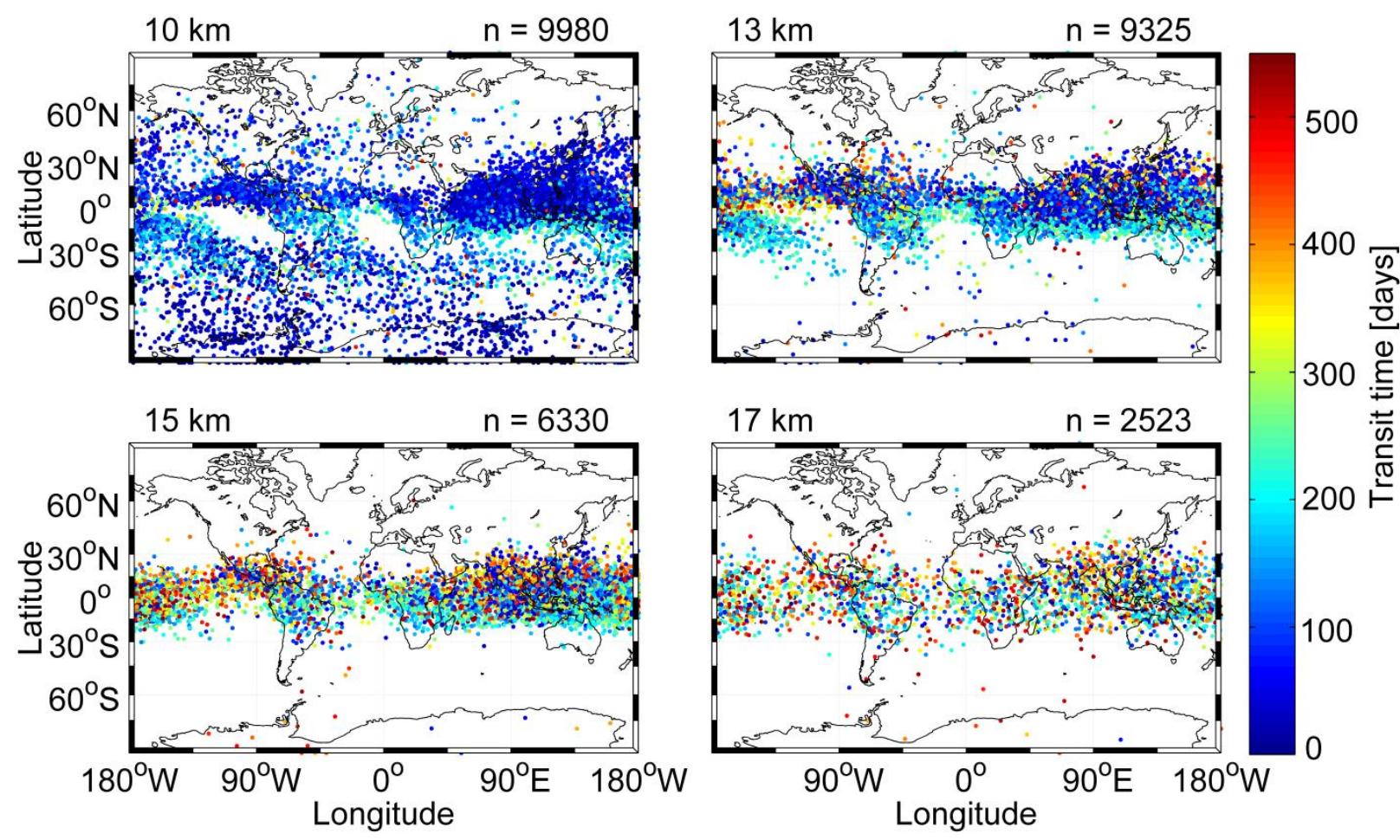

Figure S4: Trajectory positions and transit time at different altitudes for the $\mathbf{1 0 . 0 0 0}$ trajectories of the simulation of the $\mathrm{CH}_{2} \mathrm{Br}_{2}$ measurement on 23 UTC July 12, 2014. 


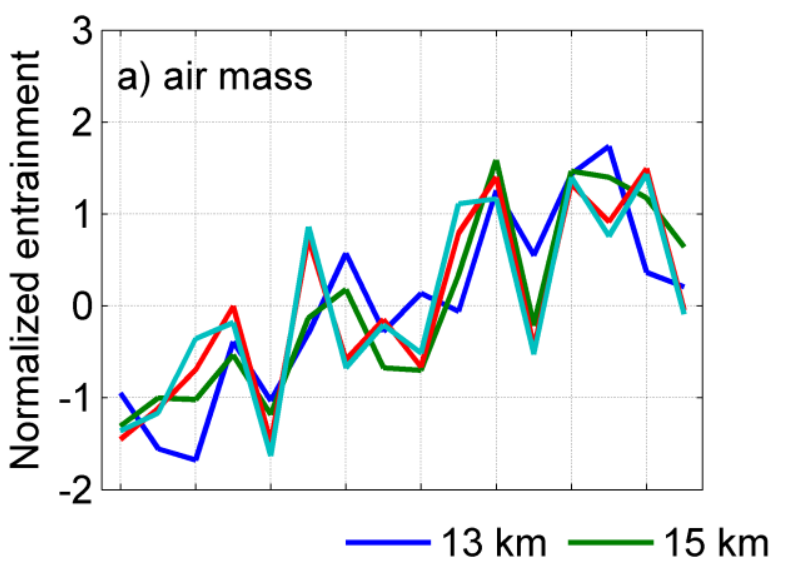

b) $\mathrm{CHBr}_{3}$
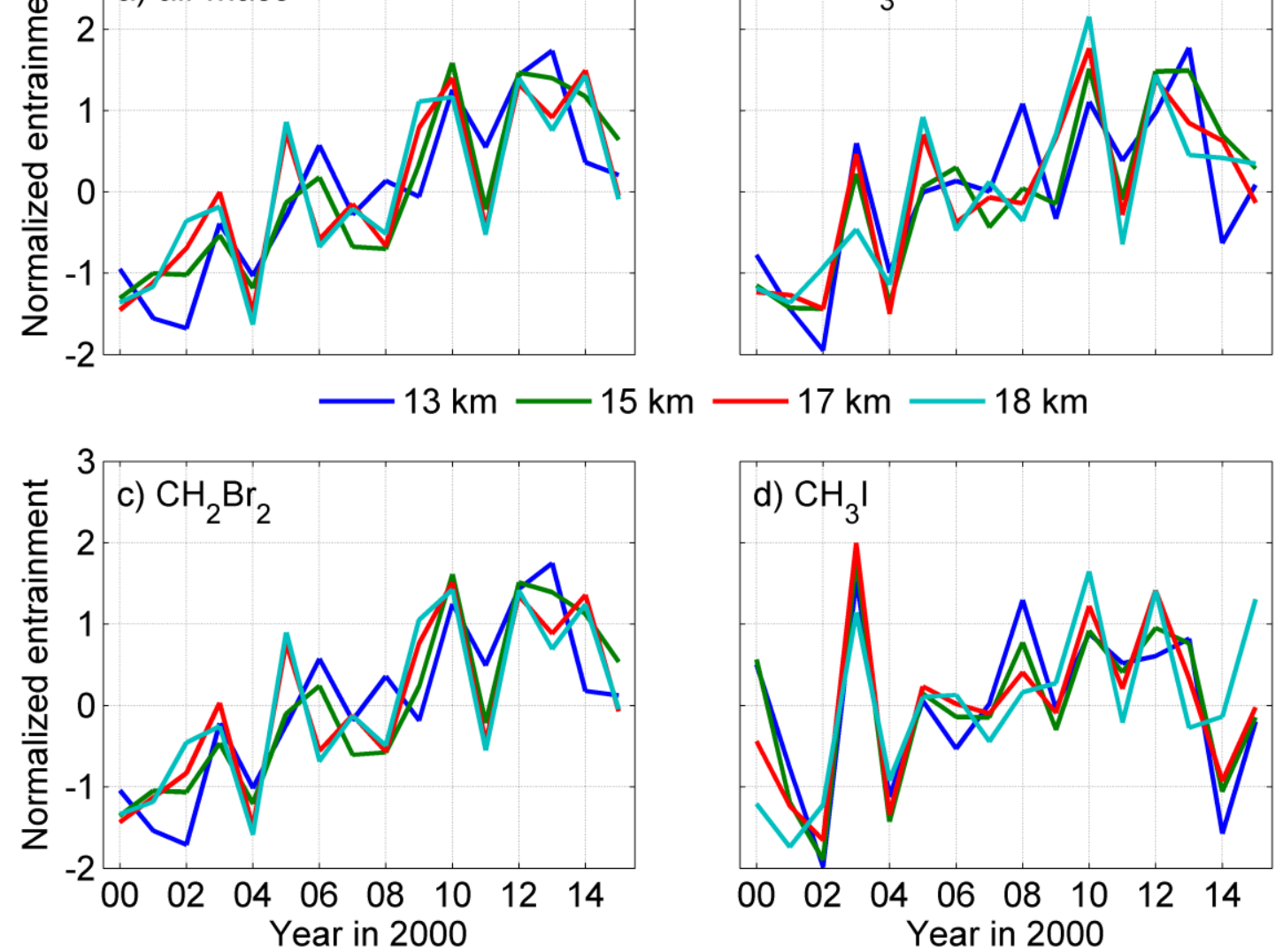

Figure S5: Normalized entrainment strength of air mass and VSLS tracers from the Indian Ocean FLEXPART setup at different heights released every day during July 2000-2015. 

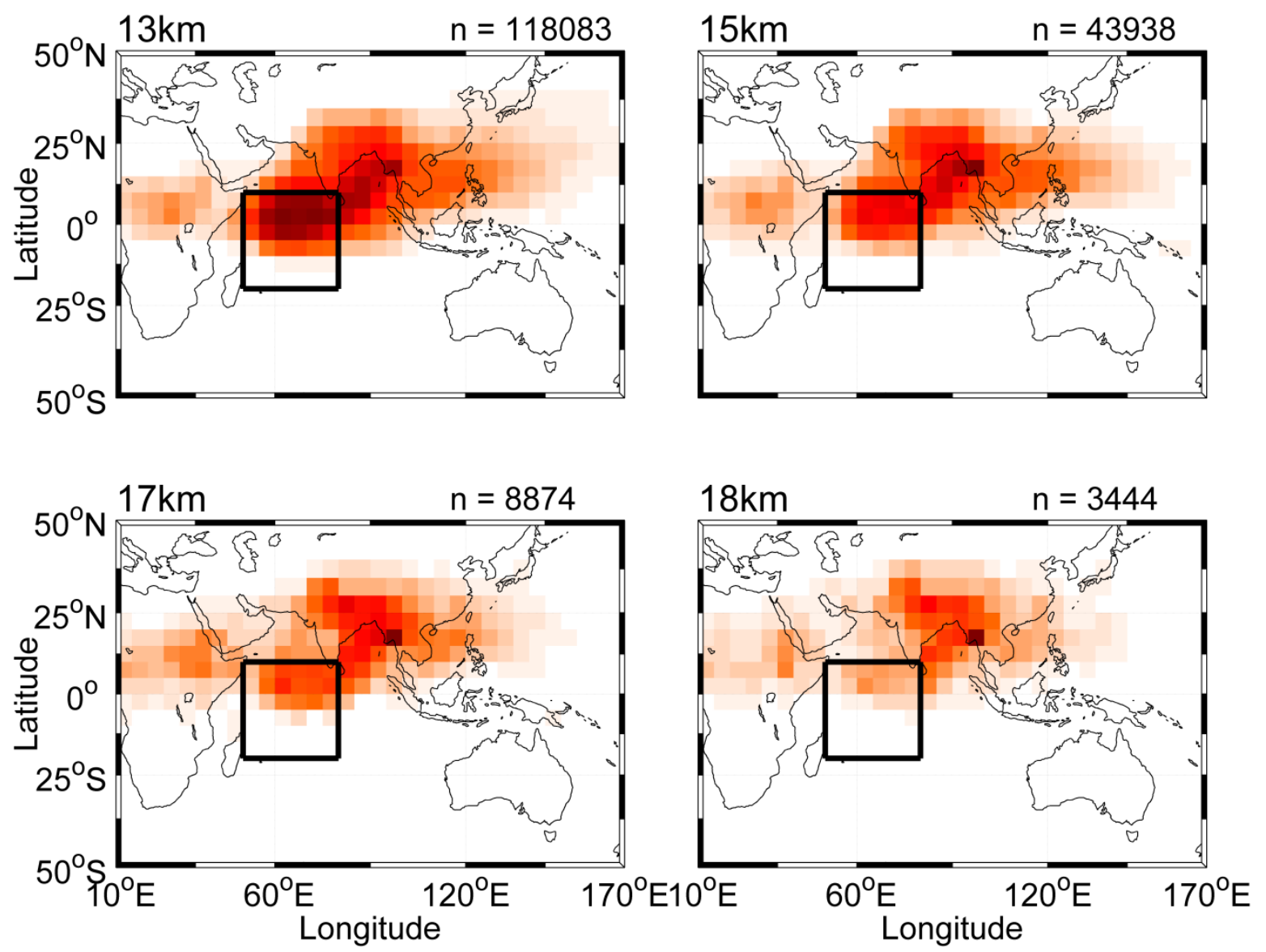

Figure S6: Entrainment regions for $\mathrm{CHBr}_{3}$ tracer at different heights for daily releases in July 20002015 from the west Indian Ocean release box (black rectangle). The height is noted in the upper left corner, while the total entrainment number is noted as $n$. 